\title{
O TINGUAÍTO DE JABOTICABAL, SP
}

\author{
J. V. Valarelli* \\ J. M. V. Coutinho* \\ J. B. M. Madureira Filho* \\ C. B. Gomes*
}

\section{RESUMO}

No município de Jaboticabal, SP, ocorre um corpo de tinguaito, de forma ligeiramente elíptica, medindo $300 \times 100 \mathrm{~m}$, intrusivo em basalto da regiđo.

Foi descoberto durante campanha de levantamento de solos, quando investigava-se a origem de mancha de Litossolo desenvolvida no meio de Litossolo Roxo, sob condiçбes geomorfológicas semelhantes.

Macroscopicamente o Tinguaíto de Jaboticabal é compacto, fanerítico e apresenta coloração variando entre cinza escuro a cinza esverdeado. Microscpicamente observa-se granulometria de fina a média, com texturas equigranular e porfirítica-poiquilítica.

Seus principais minerais constituintes são: nefelina, sanidina, augita sódica e analcita. Os minerais acessórios mais comuns săo: titano-augita, magnetita, titanita e enigmatita. São também encontrados: zircaro, anfibólio sódico, apatita, perowskita, andradita e natrolita.

Trabalhos anteriores tentaram correlacionar lavas analcimítica, intercaladas na parte inferior do Arenito Bauru (regioes de Taiúva, Piranjí a Aparecida do Monte Alto), com o corpo de Jaboticabal. O presente trabalho traz dados adicionais corroborando com esta correlação.

\begin{abstract}
The tinguaite from Jaboticabal, SP, is a nearly elliptical body $(300 \times 100 \mathrm{~m})$ intrusive into the Paraná basalts (São Bento Series). It was discovered during a soil surveying at the área, in wich under similar geomorphological conditions - a lithosoil spot (overlaying the tinguaite), surrounded by a latosoil (derived from the basalts), was developed.

Macroscopically the tinguaite is a hard, phaneritic rock dark gray to green in color. Microscopically it is fine to medium grained, with textures ranging from equigranular to porphyritic poiquilitic.

Nepheline, K-feldspar (sanidine), pyroxene (Na-augite) and analcite are the main minerals. Ti-augite, magnetite, sphene and aenigmatite make up the most common acessories. Zircon, Na-amphibole, apatite, perowskite, andradite and natrolite have also been found.

Previous work done in the area suggests a correlation between the tinguaitic intrusive from Jaboticabal and the recently discovered analcimitic lavas interbedded within the Bauru Sandstone at Taiúva, Piranji and Aparecida do Monte Alto. The Authors present new mineralogical, petrographic and chemical data supporting that correlation.
\end{abstract}

\section{INTRODUÇĀo}

Geologicamente, o Municipio de Jaboticabal está situado em terrenos mesozóicos consistindo de basaltos toléíticos intercalados em Arenito Botucatu e capeados por Arenito Bauru. A morfologia da região é de colinas com declives suaves, variando de 5 a $7 \%$, com topos aproximadamente tabulares. Os desniveis nåo atingem a $80 \mathrm{~m}$ e a altitude média é de $575 \mathrm{~m}$. O clima, segundo a classificaçَ̄o de Koppen, é o tipo Cwb. O solo predominante da regiāo é o Lotossolo Roxo, entremeado por "Solos Podzolizados Lins e Marilia". Recobrindo as colinas ocorre o Latossolo Vermelho Amarelo, fase arenosa, com passagem gradual para Latossolo Roxo na meia encosta (PINOTTI et al., 1970). 
A área estudada em detalhe abrange quatro hectares, sendo na sua maior parte intensamente cultivada, uma vez que inclui terras da Faculdade de Medicina Veterinária e Agronomia e do Horto Florestal de Jaboticabal.

Num mapeamento de solos, ao nível de Série, da área observou-se a existência de uma mancha de solo pouco desenvolvido, dentro da região mapeada como Latossolo Roxo (Fig. 1). Dada à semelhança nas condiçôes pedogenéticas, a sua ocorrência foi interpretada como uma consequêtncia da diferença de material de origem. Realmente, o estudo das caracteristicas morfológicas, fisicas e mineralógicas do perfil desse solo mostrou diferenças marcantes, quando comparadas com aquelas do Latossolo Roxo, culminando com a localização de uma rocha alcalina (tinguaito), conforme mencionado em PINOTTI et al. (1970). GOMES \& VALARELLI (1970) forneceram uma descriça petrográfica preliminar dessa nova ocorrência, assim como a sua idade $\mathrm{K} / \mathrm{Ar}$ de $54 \pm 3$ m.a.

Novos estudos foram facilitados pela construção de um trevo de acesso à Faculdade de Agronomia na Rodovia Jaboticabal - Ribeirão Preto. Ao mesmo tempo, tornaram-se disponíveis dados do levantamento geofísico efetuado com o objetivo de pesquisa de água subterrânea na área, que confirmam os estudos anteriores.

Mais recentemente, COIMBRA et al. 1981 e COUTINHO et al. (1982) relataram a ocorrência de lavas alcalinas analcimíticas intercala. das em Arenito Bauru próximo à cidade de $\mathrm{Ja}$. boticabal, sugerindo a correlação com $\mathrm{a}(\mathrm{s})$ intrusiva(s) da área.

Dessa forma, a ocorréncia de Jaboticabal ganha nova importância, a justificar o relato mais pormenorizado, objeto deste trabalho.

\section{LEVANTAMENTO DE SOLOS}

A Figura 2 resume os dados dos estudos do perfil de solo realizados em Jaboticabal pelo então bolsista R. F. Pinotti (FAPESP, Agronomia 69/896).

A área anômala de solo pouco desenvol. vido acha-se delimitada ao sul do Córrego Jaboticabal, onde, em encosta de declive constante, existe uma mancha de solo pobre (litossolo), cercada por Latossolo Roxo muito fértil (Figs. 1 e 2).

\section{GEOLOGIA}

As duas primeiras figuras e os perfis geofísicos (Fig. 3) sugerem a ocorrência do tinguaíto como um corpo discordante de conta- tos verticais, de forma provavelmente elíptica, e medindo cerca de 300 e $100 \mathrm{~m}$ ao longo de seus eixos principais. Esse corpo pode constituir-se numa "chamine" intrusiva no basalto ou, alternativamente, em uma ramificaçđo de um "stock" ou intrusão maior.

A anomalia geofísica assinalada no perfil geo-elétrico AA indica que pelo menos mais um corpo acha-se encoberto sob o aterro do aeroporto Jaboticabal.

\section{PETROGRAFIA}

As rochas alcalinas de Jaboticabal săo de coloraça cinza esverdeado, às vezes cinza escuro, faneríticas e maciças. Exibem granulação variável de fina a média e texturas diversas (equigranular, hipidiomórfica e porfirítica), sendo os minerais essenciais em ordem de abundância: nefelina, feldspato alcalino, piroxênio e analcita.

A nefelina é encontrada na forma de cristais idiomórficos, as vezes alterados nas bordas e segundo planos de clivagem. Ela forma a trama principal da rocha, juntamente com a analcita, piroxênios e sanidina (Fotomicr. 1). A analcita ocorre na forma de cristais límpidos equigranulares de contornos arredondados, enquanto a sanidina se apresenta como cristais poiquilíticos tabulares, incluindo egirina-augita, magnetita e analcita alterada (Fotomicr. 2).

Os piroxenios (variedades de egirina-augita), na forma de pequenos prismas ou mesmo de cristais aciculares, ocorrem erraticamente, concentrados em certas zonas, moldurando parcialmente contomos de analcita e como inclusరes poiquilíticas em nefelina. Apresentam cor verde característica com pleocroismo de verde-pardacento a verde escuro. Alguns raros fenocristais de piroxênio apresentam zoneamento com núcleo de titano-augita e bordas mais egirinicas escuras (Fotomicr. 2).

Os minerais acessórios incluem, além da titano-augita: esfeno, na forma de cristais idiomórficos ou como constituinte de agregados; enigmatita, como manchas de coloraçåo vermeIha escura; magnetita, perowskita, em cristais octaédricos: anfibólio de cor parda (barkevikita?), idiomórfico ou como alteraçăo de piroxênio; e apatita em pequenos prismas. Mais raramente săo encontrados zircăo, granada, natrolita (produto de alteraçāo de analcita e nefelina) e outros minerais incolores ou amarelos zirconiferos e/ou titaníferos.

Essas descriçסes concordam com as fornecidas por COIMBRA et al. (1981)e por COUTINHO et al. (1982), enquanto que GOMES \& 


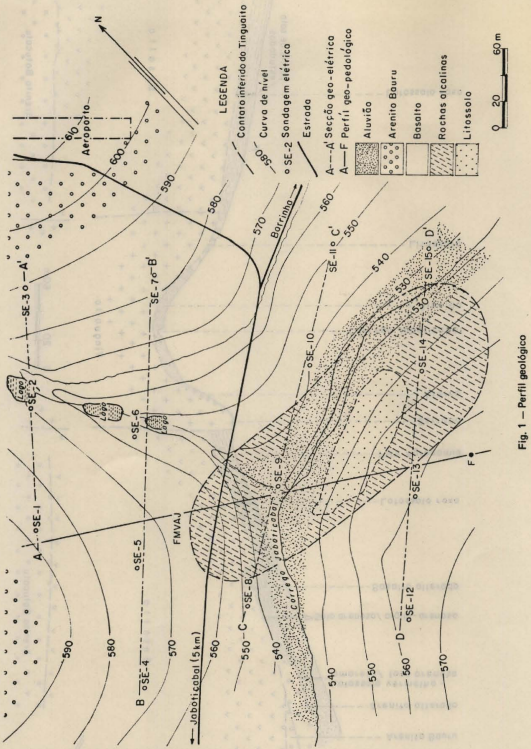




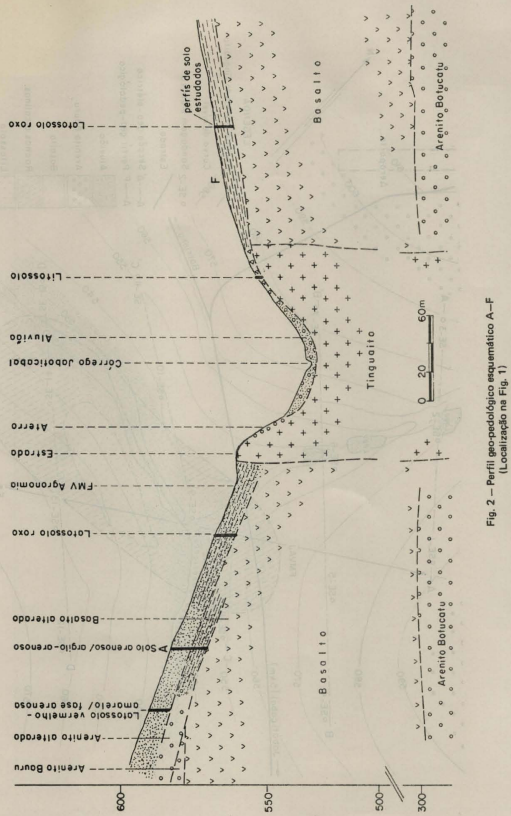



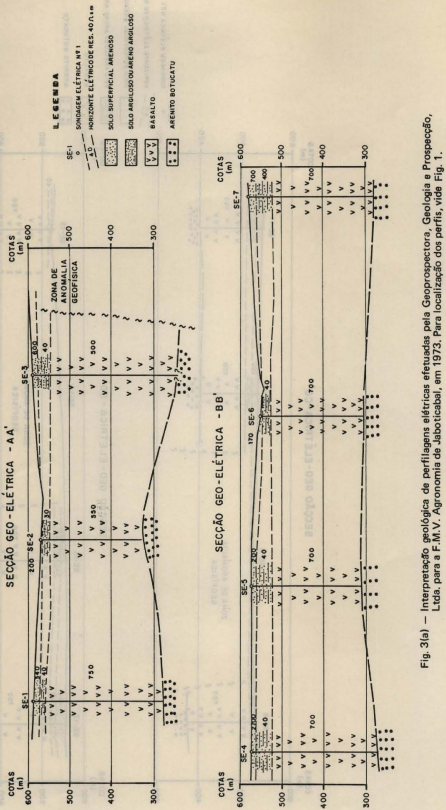


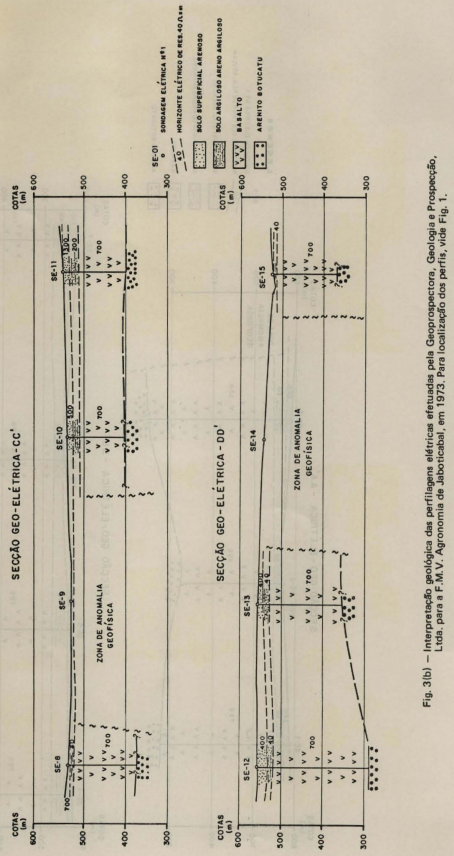




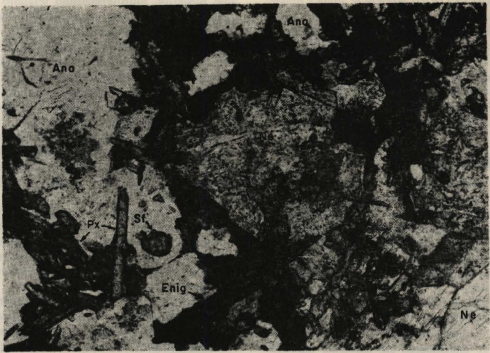

FOTOMICROGRAFIA 1 - Nefelina (Ne) ao centro e à direita, cercada de enigmatita (Enig) e incluindo opacos e piroxénios. Analcita (Ana) na parte esquerda da foto incluindo esfeno (sf), piroxênio e mancha de natrolina (Nat). $\times 40$.

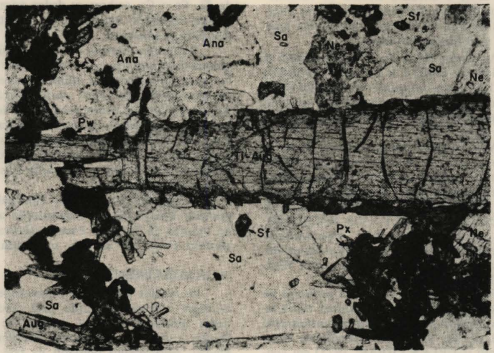

FOTOMICROGRAFIA 2 - Associaç̃o entre sanidina (Sa), analcita (Ana), nefelina (Ne) e Na-augita (Aug). Fenocristal de titano-augita com bordas de egirina numa faixa central da foto. Notar tambem a presenca de perowsikita $(\mathrm{Pw}$ ) e titanita (sf) na mesma lâmina, Piroxénios (Px e Aug) distribuem-se nos cantos da foto. $\times 40$. 
VALARELLI (1970) referem-se ainda à presença de feldspato alcalino xenomórfico (ortoclásio) e cancrinita como importantes minerais de alteração.

$\mathrm{Na}$ Tabela I podem ser vistas três análises químicas de amostras de Jaboticabal ao lado da análise calculada com base nos dados modais de COUTINHO et al. (1982). A Tabela 2 apre. senta as normas CIPW e catiônica de Barth.

\section{CONSIDERAÇÕES FINAIS}

A intrusão alcalina de Jaboticabal, embora de pequena dimensão, apresenta aspectos variáveis de granulação, textura, composição química e mineralógica, previsiveis de serem encontradas em um "neck" vulcânico, onde, além de sequêencias de cristalizaçăo, é possível esperar-se fenômenos de alteração hipógena hidrotermal.

Segundo COUTINHO et al. (1982), as relaçōes de contato entre minerais e a textura tinguaítica e poiqulítica permitem sugerir uma ordem de cristalizaçăo em ambiente hipoabis. sal, na seguinte seqüência: perowskita, magné. tita, apatita e esfeno; titano-augita e egirina-augita; nefelina e anfibólio sódico; analcita, enigmatita, egirina, zircão e acessórios zirconiferos; sanidina; e natrolita (secundária). Os mesmos autores sugerem também consangüinidade entre a intrusiva alcalina de Jaboticabal e os derrames de lavas analcimíticas intercaladas na base da Formação Bauru, em localidades próximas àquela cidade.

As idades $\mathrm{K} / \mathrm{Ar}$ de $54 \mathrm{~m}$.a. (GOMES \& VALARELLI, 1970) e de $61 \mathrm{~m}$.a. (COUTINHO et al., 1982) para o tinguaito de Jaboticabal são atribuidas a possivel hidrotermalismo terciário ou mesmo a alteração deutérica mascarando os valores reais.

Analisando os dados químicos (Tabs. 1 e 2), verifica-se que as amostras de Jaboticabal apresentam caráter fortemente insaturado com altos teores de nefelina normativa além de forsterita. Se comparados esses valores com os dados de literatura (DALY, 1933; NOCKOLDS, 1954) para rochas tinguaiticas, destacam-se as concentraçōes de $\mathrm{SiO}_{2}$ e $\mathrm{Na}_{2} \mathrm{O}$ abaixo da média, assim como altos teores de $\mathrm{H}_{2} \mathrm{O}^{+}, \mathrm{CaO}, \mathrm{MgO}$, $\mathrm{FeO}$ e $\mathrm{TiO}_{2}$ das amostras examinadas.

Essas diferenças, aliadas ao problema de dataçato $\mathrm{K} / \mathrm{Ar}$, e a aspectos texturais talvez sejam explicados por uma série de cristalizaçao normal de um sistema leucita-nefelina clinopiroxênio (GUPTA \& LIDLAK, 1973) em con. diçōes de equilibrio univariante da reação de formaçāo de tiranita, a partir de perowskita e silica de CARMICHAEL et al. (1974). Numa fase posterior, hidrotermalismo terciário aventado por COUTINHO et al. (1982), a leucita foi substituida por analcita (PEARCE, 1970; GUPTA \& FYFE, 1975), seguida de cristalização de feldspato potássico. Essas hipóteses explicariam os problemas de datação geocronológica, o problema da coexistência dos acessórios titaniferos e em particular da associação de perowskita com feldspato potássico. Explicariam também a associação principal de analcita + nefelina analcitizada das lavas de Taiúva (COUTINHO et al., 1982) em comparaçāo com a associaçāo do corpo intrusivo (conduto?) de Jaboticabal.

Outros aspectos importantes da correlação entre o quimismo e a natureza dos piroxênios e dos minerais acessórios (perowskita) sđ̄o convincentes para sugerir a consanguinidade entre o corpo tinguaítico e as lavas intercaladas no Arenito Bauru (COIMBRA et al., 1981).

Apesar de ser um corpo de pequenas dimensס̄es, as análises de trềs amostras apresentam diferenças significativas, concordando-se com COUTINHO et al. (1982) que fluidos retidos por mais tempo no corpo mais profundo de Jaboticabal levaram a variaçōes mineralógicas e sobre. tudo à formaçao de sanidina, anfibólio sódico e enigmatita. Essas diferenças acham-se salientadas nas modas constantes da Tabela 2 .

Os piroxênios pertencem à série egirina-egirina-augita, com maior ou menor conteúdo de $\mathrm{Ti}$, $\mathrm{Fe}$ e $\mathrm{Ca}$, embora os dados normativos tenham fornecido hiperstẻnio na amostra 2 e diopsídio na amostra 3.

Os autores dispōem de outros parâmetros geoquímicos que fogem ao escopo deste traba. lho, mas que poderäo ser utilizados em estudos complementares na área: caracterização do corpo intrusivo que ocorre sob o aterro do aeroporto de Jaboticabal; procura de outras possiveis ocorrências; estudos petrográficos e mineralógicos mais pormenorizados; e estudo de efeitos de contato entre o tinguarto $e$ as encaixantes (basalto e arenito).

A intrusāo tinguaítica de Jaboticabal é a primeira descoberta de manifestação alcalina no interior da Bacia do Paraná, relativamente afastada $(100-150 \mathrm{~km})$ da sua borda atual.

\section{AGRADECIMENTOS}

Os autores agradecem à Geoprospectora, Geologia e Prospecçð̃o Ltda. pela cessāo dos dados geofísicos; ao Prof. Vicente de Paula Pereira e ao Eng? Agronômo Rui Femando Pinotti, pelo auxilio prestado na fase inicial de levantamento de solos; ao Prof. Dr. Hans Schorscher, pela obtenção dos dados normativos e outros parâmetros. 
TABELA 1 - Dados químicos do tinguafto de Jaboticabal, SP

\begin{tabular}{|c|c|c|c|c|}
\cline { 2 - 5 } \multicolumn{1}{c|}{} & \multicolumn{4}{|c|}{ Amostras } \\
\cline { 2 - 5 } & 1 & 2 & 3 & 4 \\
\hline $\mathrm{SiO}_{2}$ & 44,25 & 45,03 & 44,41 & 47,0 \\
\hline $\mathrm{TiO}_{2}$ & 1,63 & 2,92 & 2,65 & 2,2 \\
\hline $\mathrm{Al}_{2} \mathrm{O}_{3}$ & 21,78 & 17,75 & 19,38 & 18,3 \\
\hline $\mathrm{Fe}_{2} \mathrm{O}_{3}$ & 6,25 & 6,21 & 5,85 & 5,6 \\
\hline $\mathrm{FeO}$ & 2,57 & 3,38 & 3,82 & 4,3 \\
\hline $\mathrm{MnO}$ & n.a. & 0,40 & n.a. & - \\
\hline $\mathrm{MgO}_{\mathrm{CaO}}$ & 2,40 & 2,18 & 1,20 & 1,8 \\
\hline $\mathrm{Na}_{2} \mathrm{O}$ & 6,08 & 5,73 & 6,57 & 5,9 \\
\hline $\mathrm{K}_{2} \mathrm{O}$ & 3,25 & 6,81 & 3,92 & 9,3 \\
\hline $\mathrm{P}_{2} \mathrm{O}_{5}$ & 4,50 & 4,67 & 4,63 & 3,2 \\
\hline $\mathrm{CO}_{2}$ & 0,13 & 0,07 & 0,49 & 0,1 \\
\hline $\mathrm{H}_{2} \mathrm{O}^{+}$ & n.a. & n.a. & 0,26 & - \\
\hline $\mathrm{H}_{2} \mathrm{O}^{-}$ & 4,92 & 3,48 & 3,07 & 1,9 \\
\hline $\mathrm{Total}$ & 2,03 & 1,70 & 2,75 & tr \\
\hline
\end{tabular}

Analistas: amostra 1 e 2: Raphael Hypólito, IG-USP.

amostra 3: Jose Salvador W. Baroni, Puriquima.

amostra 4: cálculo a partir de análises modais de COUTINHO et al. (1982).

TABELA 2 - Dados normativos do tinguaíto de Jaboticabal, SP

\begin{tabular}{|l|c|c|c|c|c|c|c|c|}
\cline { 2 - 10 } \multicolumn{1}{c|}{} & \multicolumn{4}{c|}{ Norma CIPW } & \multicolumn{3}{c|}{ Norma catiónica de BARTH } \\
\cline { 2 - 10 } \multicolumn{1}{c|}{} & 1 & 2 & 3 & 4 & 1 & 2 & 3 & 4 \\
\hline Ortoclásio & 26,59 & 27,60 & 27,36 & 18,91 & 28,63 & 28,48 & 29,55 & 18,69 \\
\hline Albita & 13,70 & 8,26 & 15,00 & 15,73 & 15,66 & 9,05 & 17,19 & 16,49 \\
\hline Anortita & 29,31 & 4,07 & 12,61 & - & 31,58 & 4,20 & 23,35 & - \\
\hline Nefelina & 7,48 & 26,74 & 9,84 & 32,82 & 9,47 & 32,44 & 12,50 & 38,13 \\
\hline Wollastonita & - & 9,98 & - & 11,95 & - & 9,87 & - & 11,32 \\
\hline Diopsídio & - & - & 4,78 & - & - & - & 2,31 & - \\
\hline Hiperstênio & - & 5,43 & - & 4,72 & - & 6,21 & - & 5,11 \\
\hline Forsterita & 4,19 & - & 0,54 & - & 2,68 & - & 0,35 & - \\
\hline Magnetita & 3,56 & 3,74 & 4,63 & 7,07 & 1,38 & 1,39 & 1,80 & 5,04 \\
\hline Hematita & 3,80 & 3,63 & 2,66 & - & 2,85 & 2,61 & 2,00 & - \\
\hline Ilmenita & 3,10 & 5,55 & 5,03 & 4,18 & 2,45 & 4,20 & 3,99 & 3,03 \\
\hline Apatita & 0,31 & 0,17 & 0,16 & 0,24 & 0,29 & 0,15 & 1,11 & 0,21 \\
\hline Outros & 0,82 & - & 0,59 & 2,10 & - & - & 0,71 & 1,20 \\
\hline Total & 92,86 & 95,17 & 84,20 & 97,72 & 94,99 & 98,60 & 94,86 & 99,22 \\
\hline
\end{tabular}

Outros; coríndon, calcita ou acmita 


\section{REFERÊNCIAS BIBLIOGRÁFICAS}

CARMICHAEL, I.S.E.; TURNER, F.J.; VERHOOGEN, J. (1974) - Igneous Petrology. McGraw-Hill

COIMBRA, A.M.; COUTINHO, J.M.V ; BRANDT NETO, M.; ROCHA, G.A. (1981) - Lavas fonoliticas associadas à Formaçóo Bauru no Estado de São Paulo, 30 Simp. Reg. Geol., Curitiba, PR, Atas, $1: 324-328$.

COUTINHO, J.M.V.; COIMBRA, A.M.; BRANDT NETO, M.; ROCHA G.A. (1982) - Lavas alcalinas analcimiticas associadas ao Grupo Bauru $(K-b)$ no Estado de Sø̄o Paulo, V Congr. Latin, Geologia, Buenos Aires (1982), tomo II, 185-196.

DALY, R.A. (1933) - Igneous Rocks and the Depths of the Earth. McGraw-Hill, New York.

GOMES, C.B. \& VALARELLI, J.V. (1970) - Nova ocorrència de rochas alcalinas no Estado de Sä́ Paula. XXIV Congr. Bras. Geol.,.Brasília, DF, Resumos, p. 336-337.

GUPTA, A.K. \& Fyfe, W.S. (1975) - Leucite survival: The alternation to analcite. Canadian Mineral., 13: $361-363$.

GUPTA, A.K. \& LIDIAK, E.G. (1973) - The system diopsidenepheline-leucite, Contr. Mineral. Petrol., 41:231-239.

NOOCKOLDS. S.R. (1954) Average chemical composition of some igneous rocks. Geol. Soc. Am. Bull. $65: 1007$. -1032 .

PEARCE, T.H, (1970) The analcite-bearing volcanic rocks the Crowsnest formation, Alberta. Can. J. Earth Sci., 7: 46-66.

PINOTTI, R.F. $(1969,1970)$ - Relatórios de Bolsa de Iniciaçato Clentifica. FAPESP, Processo 69/896.

PINOTTI, R.F.; CORSINI, P.C.; MADUREIRA FILHO, J.B.; VALARELLI, J.V. (1970) - Levantamento de solos contribuindo para descoberia geológica. XXIV Congr. Bras. Geol., Brasilia, DF, Resumos, p. 59. 